\title{
PHYSICAL MODEL EXPERIMENTS ON RECLAMATION PROJECT OF FANGCHENG PORT
}

\author{
Xiaodong Zhao ${ }^{1}$, Jinrong $\mathrm{Ma}^{2}$, Xiangming Wang $^{3}$
}

\begin{abstract}
Tidal flat reclamation works is an effective way to relieve the contradiction between supply and demand of land in the coastal region. The reclamation project in the bay will decrease tidal current velocities, change tidal currents field, then slowdown the water exchange in the bay, which will influence water quality in the bay and increase sediment deposit at navigation channels. To study impacts of hydrodynamic environmental and sediment movement due to reclamation projects in Fangcheng Port, the physical model for tide-current and sediment was constructed in NHRI. The horizontal scale and vertical scale of the Fangcheng Port model is $1 / 660$ and 1/100 respectively. The siltation in the bay and channels mainly caused by suspended load transport under the action of tidal currents and waves.The ability of water exchange in the bay is discussed by simulating sewage diffusion characteristics before and after reclamation projects in the bay. The physical model test results are shown the total tidal volume is decreased by $20 \%$ after the reclamation plan, of which $17.5 \%$ reduction in the East Bay, $2.5 \%$ in West Bay. The tidal currents field in the channel are discussed. The sedimentation rate increases $3-10 \mathrm{~cm} / \mathrm{a}$ in navigation channels and basins of Fangcheng Port.
\end{abstract}

Keywords: tidal prism; water exchange; sediment; reclamation;Fangcheng bay

\section{INTRODUCTION}

Tidal flat reclamation works is an effective way to relieve the contradiction between supply and demand of land in the coastal region. It has tremendous social and economic efficiency. But reclamation project in a bay will make some impacts on hydrodynamic conditions, sediment movement, the ability of water exchange, and ecological environment in the bay.

Fangcheng Port is located on the north shore of the Beibu Wan in Guangxi. Fangcheng Port is a shallow water bay with wide water area, large tidal range, small wave, and little sedimentation. North-south zonal Yuman Island is in the middle of the bay, with a length of $8.5 \mathrm{~km}$, width of $1.5 \mathrm{~km}$. Yuman Island divides Fangcheng Port into West Bay and East Bay. The area of East Bay and West Bay is $110 \mathrm{~km}^{2}$ and $35 \mathrm{~km}^{2}$ respectively (Fig. 1). Natural deep water in Fangcheng bay is smaller. Most of the region is the inter-tidal beach. The $5 \mathrm{~m}$ water depth line is basically located along the navigation channel, which is dredged to deepen the water depth more than $10 \mathrm{~m}$. Sand bar is distributed on the entrance of the bay.

A large-scale reclamation project inclding a steel factory, Yuman Island harbour projects are planned in Fangcheng Port. The total area of the reclamation plan is about $30 \mathrm{~km}^{2}$ (Fig.2). The reclamation project in the bay will decrease tidal currents, change tidal currents field, then change the ability of water exchange, which will influence water quality in the bay and increase sediment deposit at navigation channels.

\section{Hydrology and Sediment}

The tide of Fangcheng Bay is a mixed tide, there are $6 \sim 8$ days for neap tide a month, which is belong to irregular semidiurnal tide, and the rest is regular diurnal tide.The maximum spring tidal range exceeds $4.8 \mathrm{~m}$. The tidal current at outer of the mouth of bay is weak. The tidal velocity increases on impact of terrain in the bay as well as reciprocating flow. The ebb current is larger than flood current in the bay during spring tide and mean tide.

Fangcheng Port is the bay of port, with the current for the irregular diurnal current, which is, large and middle current is diurnal current and neap current is semidiurnal tide, the tide is dominated by ocean currents. The trend of the open waters outside sand bar has a characteristic of rotating, the velocity is low, and the mainstream line is consistent with the tidal wave propagation. The velocity increases on impact of terrain in the bay as well as reciprocating flow in the sand bar and larger velocity along waterways axis of the sand bar nearly. The maximum current velocity was generally $0.5 \mathrm{~m} / \mathrm{s} \sim 0.8 \mathrm{~m} / \mathrm{s}$ at the current points of the mouth and inner of the bay (V5 V11), $0.2 \mathrm{~m} / \mathrm{s} \sim 0.35 \mathrm{~m} / \mathrm{s}$

1 River and Harbor Engineering Department, Nanjing Hydraulic Research Institute (NHRI), 223 Guangzhou Road, Nanjing, China, 210029, China

2 River and Harbor Engineering Department, Nanjing Hydraulic Research Institute (NHRI), 223 Guangzhou Road, Nanjing, China, 210029, China

3 River and Harbor Engineering Department, Nanjing Hydraulic Research Institute (NHRI), 223 Guangzhou Road, Nanjing, China, 210029, China 
for extraoral measured points (V1 V4), the vertical mean velocity of the ebb tide was larger than that of the flood tide during the spring and middle tide, shown in Fig. 2.

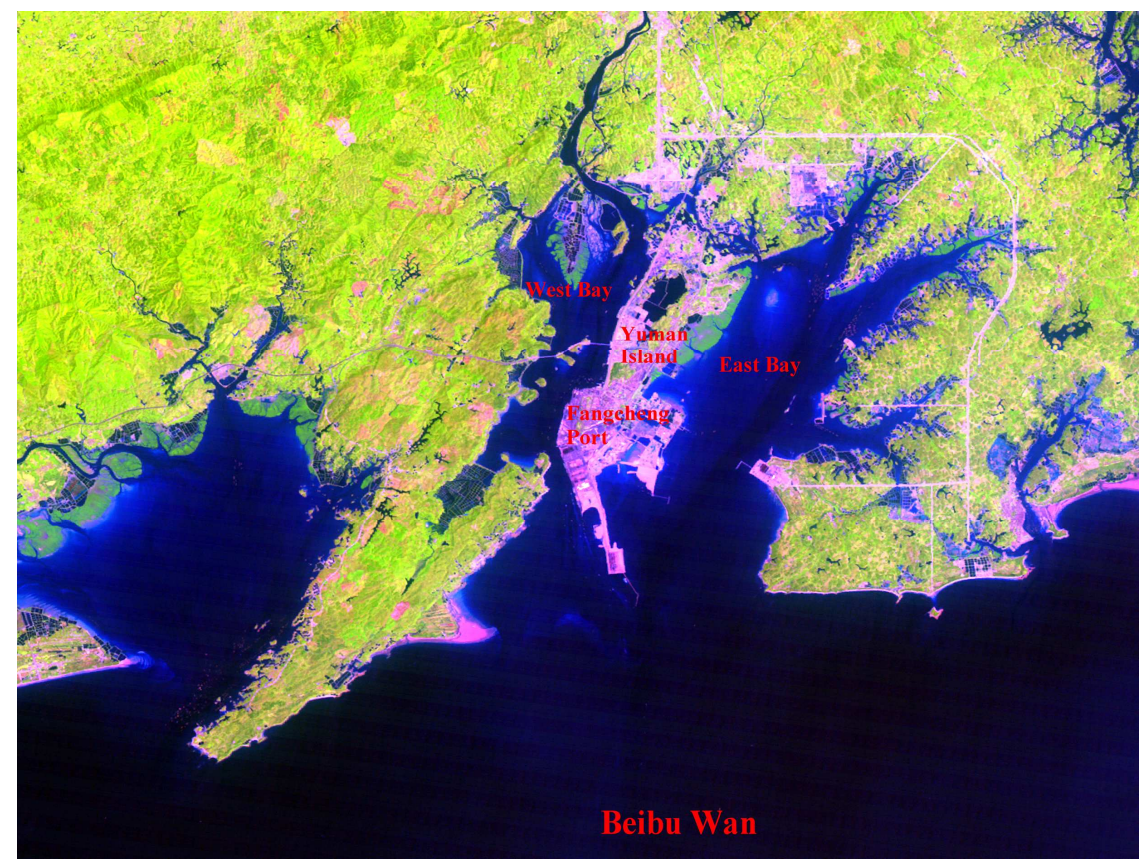

Fig. 1 Location of the Fangcheng Port

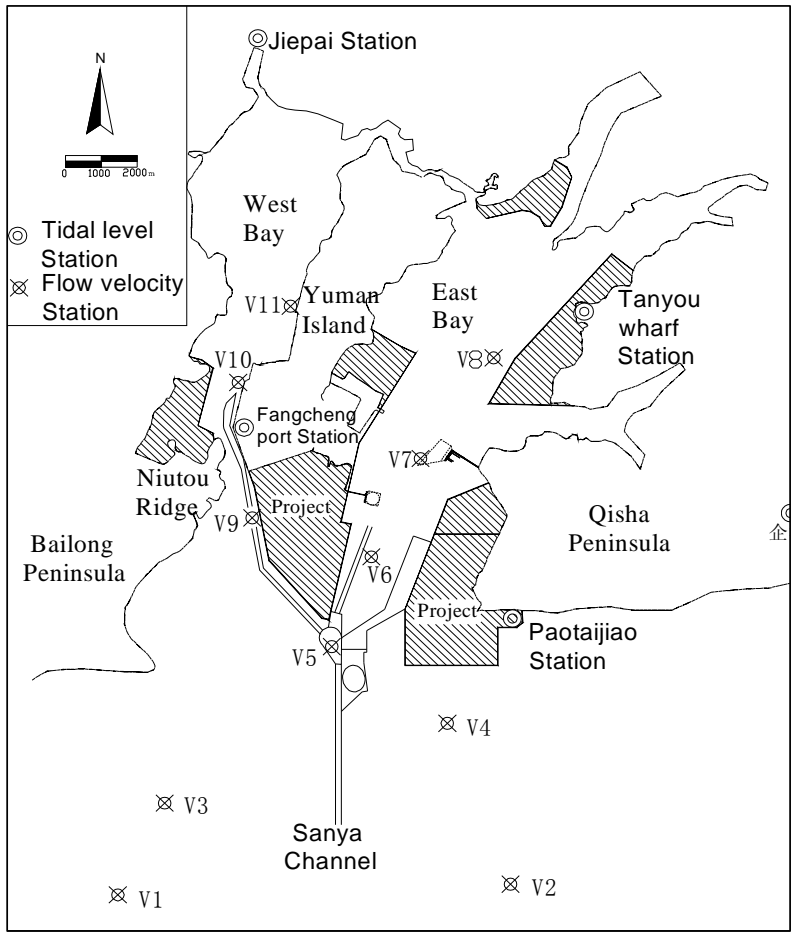

Fig. 2 Plan of Reclamation projects in Fangcheng Bay

The source of sediment deposited at the channel come mostly from outside of the bay. Sediment from rivers is another sediment source in rainy season. The more sediments flow into channel by flood current in stormy weather days.Sediment come from outside of the bay will enter and deposit at inner 
harbor by flood current. Results of deposit depth rate indicated $20 \mathrm{~cm} / \mathrm{yr}$ at approach channel and anchorage of outer channel in 2006.9 2008.5. Long-term observation SS concentrations are analyzed. The SS concentration in winter and summer is about $25 \mathrm{mg} / \ell$ and $36 \mathrm{mg} / \ell$ respectively due to the different wind and wave in different season. There are 75 stations for bed sediment sampling in the bay. Most of bottom materials in the bay are composed of sand and silt. The diameter of bed load $\left(\mathrm{d}_{50}\right)$ is about $0.015-0.58 \mathrm{~mm}$. The grain size distributions at dredged inner harbor and shoal region of the bay are silt and mud due to suspended load sedimentation.

\section{Model Design}

\subsection{Similarity conditions of tidal currents and sediment}

From the equations of tidal current movement, the conditions of similarity for the tidal currents between modal and prototype expressed as follow:

$$
\begin{aligned}
& \lambda_{u}=\lambda_{h}{ }^{1 / 2} \\
& \lambda_{c}=\left(\frac{\lambda_{l}}{\lambda_{h}}\right)^{1 / 2}
\end{aligned}
$$

In which $\mathrm{u}$ is current velocity; 1 is horizontal length; $\mathrm{h}$ is water depth; $\mathrm{C}$ is coefficient of Chezy resistance.

In estuaries and coastal regions, the seabed scour and siltation mainly caused by suspended load. Therefore, it has an important meaning to simulate suspended load transport in the model. In order to ensure the suspended sediment transport in the model be similar to that in prototype, the following similarity items should be satisfied.

$$
\begin{gathered}
\lambda_{\omega}=\lambda_{u} \lambda_{h} / \lambda_{l} \\
\lambda_{s}=\lambda_{s_{*}}=\frac{\lambda_{\gamma_{s}}}{\lambda_{\left(\gamma_{s}-\gamma\right)}} \\
\lambda_{t_{s}}=\frac{\lambda_{\gamma_{0}} \lambda_{h}}{\lambda_{s} \lambda_{\omega}}=\frac{\lambda_{\gamma_{0}} \lambda_{l}}{\lambda_{s} \lambda_{h}^{1 / 2}}
\end{gathered}
$$

In which $\mathrm{s}$ is SS concentration; $\omega$ is settling velocity of suspended load (or flocculation settling velocity when flocculation occurs); $\mathrm{s}_{*}$ is the sediment transport capacity of tidal currents; $\gamma$ and $\gamma_{\mathrm{s}}$ are the unit volume weight of sea water and sediment particles respectively; $\gamma_{0}$ is the dry sediment density on bed surface; $\lambda_{t}$ is time scale of seabed deformation caused by suspended load.

For bed load, the similarities of sediment discharge, incipient motion and particle settling must also be considered. The similarity scales for bed load as follows:

$$
\begin{gathered}
\lambda_{v_{c}}=\lambda_{v} \\
\lambda_{G}=\lambda_{G_{*}} \\
\lambda_{\omega}=\lambda_{h} \lambda_{v} / \lambda_{l} \\
\lambda_{t_{b}}=\lambda_{\gamma_{0}} \lambda_{l} \lambda_{h} / \lambda_{G}
\end{gathered}
$$

In which $v_{c}$ is the velocity of incipient motion of bed sediments; $G$ is bed load discharge; $\lambda_{t_{b}}$ is time scale of bed deformation caused by bed load.

\subsection{Model Sediments and Scale Values of Model}

Based on the analysis of suspended load data and deposited material in the bay, most of suspended sediment in the project site is silt. The average grain diameter $\mathrm{d}_{50}$ is about $0.02 \mathrm{~mm}$. From previously published results, the suspended sediment with particle sizes less than $0.03 \mathrm{~mm}$ would settle in the form 
of flocculation in salt water. The settling velocity of fine particles in flocculation is $0.04 \mathrm{~cm} / \mathrm{s}$. According to experience of physical model test on coast and estuary region, a wooden powder with unit weight $1.16 \mathrm{~g} / \mathrm{cm}^{3}$ and median grain diameter $0.065 \mathrm{~mm}$ is taken as suspended sediment in model test.

Considering the laboratory conditions, the full-field physical model is designed to geometrically distorted with a ratio 1:6.6 of horizontal length to vertical depth. The horizontal scale is 1:660 and the vertical scale is 1:100. According to above relationship of similarity, the tidal current and sediment scale values can be calculated. The detail scales of Pyeongtaek Port model are listed Table 1.

\begin{tabular}{|lc|c|}
\hline \multicolumn{3}{|c|}{ Table 1. Scale values of Fangcheng Port model } \\
\hline \multicolumn{1}{|c|}{ Scales } & Values \\
\hline Horizontal & $\lambda_{l}$ & 660 \\
\hline Vertical & $\lambda_{h}$ & 100 \\
\hline Velocity & $\lambda_{v}$ & 10 \\
\hline Current time & $\lambda_{t}$ & 66 \\
\hline Roughness coefficient & $\lambda_{n}$ & 0.84 \\
\hline Settling velocity & $\lambda_{\omega}$ & 1.52 \\
\hline Incipient velocity & $\lambda_{v_{c}}$ & 10 \\
\hline Suspended load concentration & $\lambda_{s}$ & 0.22 \\
\hline Timescale for sedimentation of suspended load & $\lambda_{t_{s}}$ & 920 \\
\hline
\end{tabular}

The model scope included the entire bay area outer to the depth of $18 \mathrm{~m}$. The tidel level observation stations (4 stations) and current observation points(11 points) in Fangcheng Bay are shown in Fig.2.The observed data of spring tide on May 19 th -20th, 2007 and neap tide on May 24 th -25 th ,2007are used for tidal levels and currents verification test of the model. Fig.3 is a image of the physical test.

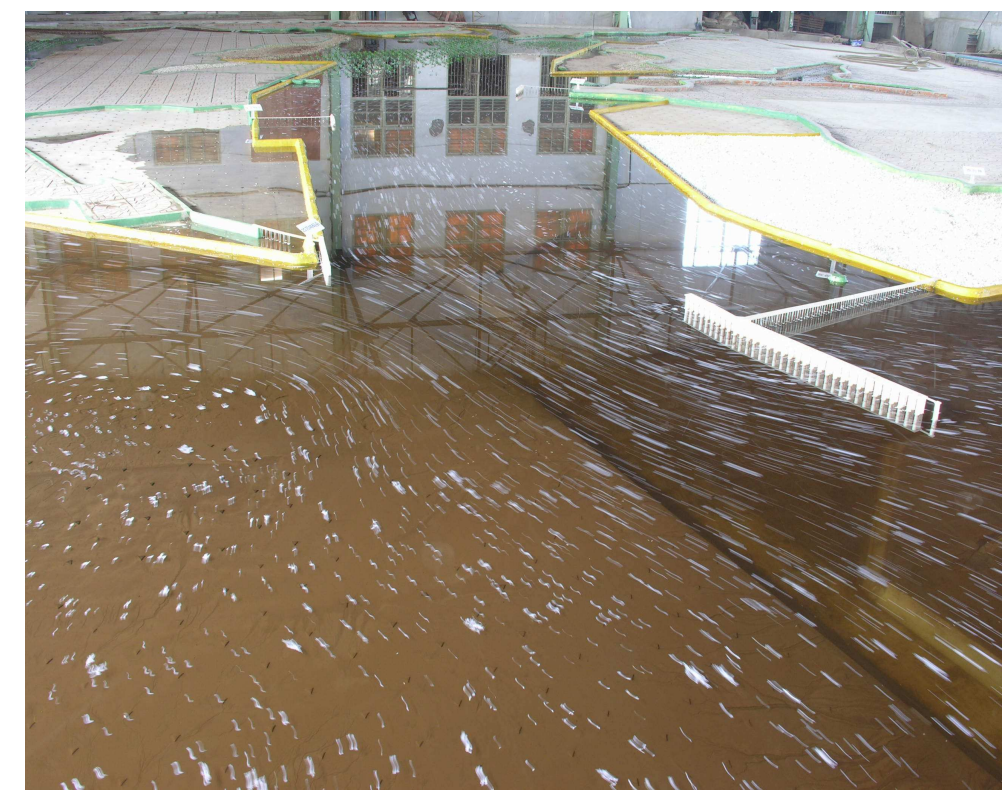

Fig. 3 Image of the physical test

The ability of water exchange in West Bay and East Bay of Fangcheng Port is discussed by means of particle tracer and dilution multiple of pollutants, and the change is predicted after reclamations. According to previously published results andexperience, salt solution of low concentration which is 1 
$\% o$ is used to simulate pollutants in the model, whose specific gravity is close to the sewage, can achieve very good test results, with the way of constant continuous surface emission.

The calculation of the dilution multiple after sewage discharge, dilution, mixing, transferring and spreading to every point in the waters is determined by the relationship between concentration and electrical conductivity measured by conductivity meter.

$$
S=K_{\mathrm{s}}-K_{0} / K-K_{0}
$$

Where, $K$ is the conductivity measured at the sampling points in the model, $K_{s}$ is that of wastewater discharged initially, and $K_{0}$ is that of the background water. Sewage concentration field in the model test is expressed by the dilution multiple of sampling points. Changes of pollution, diffusion and transport of the pollutants can be reflected by changes of dilution multiple in the same draining condition.

\section{Results of the model tests}

The physical model test results are shown the total tidal volume is decreased by $20 \%$ after the reclamation plan, of which $17.5 \%$ reduction in the East Bay, $2.5 \%$ in West Bay.

The sedimentation rate increases 3-10 cm/a in navigation channels and basins of Fangcheng Port. The source of sediment deposited at inner harbor and channnels come mostly from outside of the bay. Mean SS concentration is about 30mg/l according to observation data. Suspended sediment of model was supplied by suspended sediment supplying system. According to observation data, the deposit depth rate is $20 \mathrm{~cm} / \mathrm{yr}$ at approach channel and anchorage of outer channel in 2006.9 2008.5. Sedimentation test in exist case is a verification test. Test period may modify according to result of sedimentation rate of suspended load. Sedimentation rate at inner harbor and outer channel is $23-30 \mathrm{~cm} / \mathrm{yr}$ in the case of reclamation plan.

The ability of water exchange between inside and outside in the bay was studied by analyzing the trajectory of tracer particles and concentration distributing of pollutants diffusion.

Two sewage outfalls both are laid in the East and West Bay of Fangcheng Bay, which the sewage volume is 400,000 tons a day and sewage flow of generalizability in the model is controlled by the glass rotameter. There are 18 sampling points in West Bay and 22 sampling points in East Bay. The sampling are distributed from the bay mouth to near the top of the bay along the deep channel .Outfalls and sampling points are shown in Fig.4. In each case test sampling is carried out lasting 4.5 tidal cycles after waste water discharging so that the concentration of the effluent is close to a stable state.

The bay is divided into the segment from the sewage outfall to the top and the segment from the sewage outfall to the entrance so to analyze separately the impact of sewage diffusion on inner of Fangcheng Bay. From Table 2 that is the polluted length in East Bay and West Bay, it can be seen that the concentration of pollutants is higher near the top of the bay, the impact of sewage discharge on this region is larger, which is relevant that these sampling points are located near the outfall, and at the same time it is illustrated that the water exchange capacity of the top of bay is weak.

The water exchange capacity from the sewage outfall to the entrance is stronger than that from the sewage outfall to the top, and the farther the sampling points are from the entrance, the smaller the concentration of sewage is, sewage spreading has little impact on the bay close to the entrance. The polluted length in East Bay changes little before and after filling but only at the entrance the length is lengthened $2.4 \mathrm{~km}$ during spring tide.

Comparison of dilution multiple changes before and after reclamation engineering in East Bay, from the sewage outfall to the top it reduced averagely 53\% during spring tide, $14 \%$ for neap tide; while from the sewage outfall to the entrance it decreased $41 \%$ during the spring tide, $9 \%$ for neap tide, and the rate of change are all smaller than that at the entrance. The difference is that dilution multiple increased 35\% near the sewage outfall (19\#-22\#) during neap tide. From this analysis, change of the multiple from the sewage outfall to the top is larger than that from the sewage outfall to the entrance after reclamation engineering. This is mainly because that the power of current is weaker near the top of the bay, the water exchange capacity is on the weak, and the area of the bay decreased by $24.6 \%$ after filling, which significantly weakened the power of the current and reduced the water exchange capacity. However, the water outside sea can exchange more fully from the sewage outfall to the entrance, so the change is smaller. On the contrary, the neap tidal change increased at the sewage 
outfall is shown that the change caused by current field is less than sewage self-purification capacity.

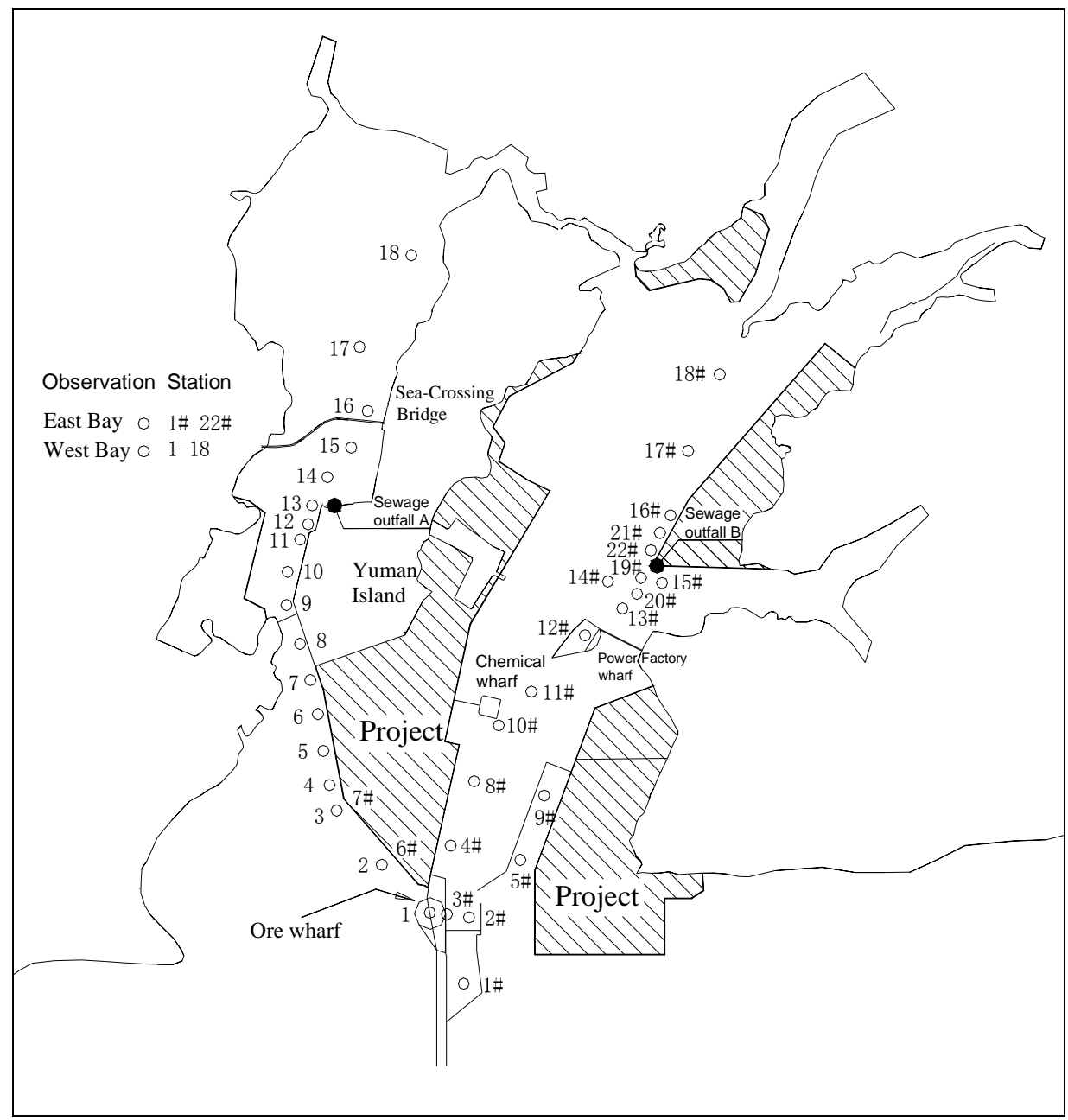

Fig. 4 Layout of Sewage Outfalls and Sampling Points in the Model

\begin{tabular}{|c|c|c|c|c|c|c|}
\hline \multicolumn{2}{|c|}{ Table 2 } & \multicolumn{2}{c|}{ The Polluted Length in East Bay and West Bay } & \multicolumn{2}{c|}{ (km) } \\
\hline \multirow{2}{*}{ way } & \multicolumn{2}{|c|}{ Exist case in East Bay } & \multicolumn{2}{|c|}{ After reclamation case in East Bay } & \multicolumn{2}{c|}{ West Bay } \\
\cline { 2 - 7 } & $\begin{array}{c}\text { Spring tide } \\
(S<100)\end{array}$ & $\begin{array}{c}\text { Neap tide } \\
(S<50)\end{array}$ & $\begin{array}{c}\text { Spring tide } \\
(S<100)\end{array}$ & $\begin{array}{c}\text { Neap tide } \\
(S<50)\end{array}$ & $\begin{array}{c}\text { Spring tide } \\
(S<100)\end{array}$ & $\begin{array}{c}\text { Neap tide } \\
(S<50)\end{array}$ \\
\hline $\begin{array}{c}\text { Up to the top } \\
\text { of the bay }\end{array}$ & 4.0 & 4.1 & 4.0 & 4.0 & 5.3 & 5.3 \\
\hline $\begin{array}{c}\text { Down to the } \\
\text { mouth of the bay }\end{array}$ & 6.5 & 4.4 & 8.9 & 4.4 & 6 & 2.1 \\
\hline
\end{tabular}

\section{Conclusions}

The tidal currents field and sediment deposit in the channel are discussed. The ability of water exchange between inside and outside in the bay was studied by analyzing the trajectory of tracer particles and concentration distributing of pollutants diffusion. The sedimentation rate increases $3-10 \mathrm{~cm} / \mathrm{a}$ in navigation channels and basins of Fangcheng Port. A approprite entrance width of $2100 \mathrm{~m}$ at Eest Bay and recommended scheme of the reclamation plan in Fangcheng Port were proposed. 


\section{ACKNOWLEDGMENTS}

The peoject is financially supported by Ministry of Water Resource's Nonprofit Special Funds for Science Research of China (Grant No. 200801016). The writers benefitted greatly from stimulating discussions with, Huifeng Chen, Xing Yang.

\section{REFERENCES}

Chen,J.Y.2000. Coastal reclamation works in China. China WaterPower Press (in Chinese)

Zhao, X.D. 2008. Physical model test report of tide-current and sediment on Fangcheng Port. Nanjing Hydraulic Research Institute (in Chinese).

Huang J.W. and WEI H.P. 2002. Research on Model Test Equipment for Sewage Dilution and Diffusion of Ocean Disposal. Journal of TongJi University. Vol. 30, No. 12, pp1488-1491 (in Chinese)

Wang M.J., Luo L, Huang X.X. 2006. Similarity of Transverse Mixing of Water Pollutant between Distorted Model and Prototype River. Journal of Sichuan University, Vol. 38, No. 4, pp15-18 (in Chinese) 